\title{
The Impact of Inclusive Finance on Household Risk Financial Market Participation
}

\author{
Zhao Xinxin*, Ma Yifei, Li Siqi, Si Zhongjie \\ School of Economics, Shandong University, Jinan, China \\ Email address: \\ xinxinzh@126.com (Zhao Xinxin) \\ ${ }^{*}$ Corresponding author
}

\section{To cite this article:}

Zhao Xinxin, Ma Yifei, Li Siqi, Si Zhongjie. The Impact of Inclusive Finance on Household Risk Financial Market Participation. International Journal of Economics, Finance and Management Sciences. Vol. 9, No. 4, 2021, pp. 165-173. doi: 10.11648/j.ijefm.20210904.14

Received: August 5, 2021; Accepted: August 30, 2021; Published: September 3, 2021

\begin{abstract}
It is a general rule that households will pay significantly more attention to management of family assets since their income has experienced a continuous increase, and Chinese families are no exception. With the Opening and liberalization of financial market in China, policies about financial inclusive service are put forward after the first decade of the $21^{\text {st }}$ century to support household finance. However, there are still rooms for improvement in the implement of the policy. It is still not very clear that how we can enhance its supposed role in family financial decisions and whether it has equal utility to household in various financial conditions and characters. So research must be made to better evaluate the effect of inclusive finance and help promoting its development. Based on 2017 Chinese Household Financial Survey (CHFS) data, the choices of household financial allocation including the possibility of risk financial market participation and the proportion of risk financial assets held by households are studied. By using factor analysis to combine both traditional and digital factors, a new inclusive finance index is calculated and the fact that inclusive finance can increase the possibility of household risk financial market participation is further proved. Moreover, by subdividing the sample, it is found that the utility of inclusive finance is greater in rural areas, among low-income households and in central and western China, and that the utility in urban areas is determined by household age structure, income level and financial literacy. As to the influence mechanism, inclusive finance can change household's choice of asset allocation by increasing their financial literacy, which is measured by related questions from the questionnaire. Since inclusive finance is widely confirmed to promote the rational allocation of financial assets, the development of inclusive finance in rural areas, among low-income households and in central and western China should be more primarily supported to better tap their potential in financial sector, while the development in urban areas should be processed together with the increase of income and the popularized of financial knowledge.
\end{abstract}

Keywords: Inclusive Finance, Household Finance, Risk Financial Market Participation, Financial Literacy

\section{Introduction}

Chinese Household Financial Survey, initiated by Southwestern University of Finance and Economics in 2011, shows that though the general participation rate is still relatively low, the risk financial market participation of Chinese household is increasing. With the development of Chinese financial market and the revolution of Chinese financial system, household participation of financial market and investment of risk assets is getting more and more attention. Existing studies have shown that family financial asset selection is related to family size, age, education level, health status, marital status, financial knowledge and other family natural characteristics, and is also related to social factors such as social insurance, relationship network, Internet popularity, and so on. These factors, especially social and economic factors, are closely related to inclusive finance.

The concept of inclusive finance has been put forward by the United Nations since 2005, and the concept recognized in China now comes from the "Implementation of the Development Plan for Inclusive Finance (2016-2020)" issued by the State Council. It refers to the requirement of equal opportunity and the principle of business sustainability and the provision of appropriate and effective financial services at an affordable cost to all segments and groups of society in need of financial services [12]. In this paper, the factor 
analysis method is used to construct the financial inclusion index as the measurement of the level of financial inclusion development in the region where the family lives. After that, the Probit and Tobit models are used to study the impact of financial inclusion on the family's participation in the risky financial market and the proportion of risky financial assets, the heterogeneity and influencing mechanism is analyzed and several policy suggestions related to the development of inclusive finance are given.

\section{Literature Review}

Existing studies have shown that the choice of family financial assets is related to the basic characteristics of the family, including family size, age, education, marital status, health status, etc. For example, age is significantly correlated with household risky financial asset selection, but there is no consensus on the type and degree of correlation in academic circles. According to most viewpoints, the relationship between family risky financial asset selection and age is obviously inverted "U" shaped, that is, the proportion of risky financial assets held in young people is low, increases year by year with the growth of age, peaks around retirement, and then declines year by year, with a life cycle effect (Bertaut and Haliassos, 1997) [2]. The research of He Wei and Wang Xiaohua (2021) shows that household wealth and income are the premise of household savings and risky financial asset allocation, and also an important embodiment of risk tolerance. Generally speaking, the proportion of households saving financial assets and risky financial assets is positively correlated with the wealth owned by households [5].

Some scholars have also studied the relationship between real estate, social insurance, social network and family financial asset selection. The research of Kevin E. Beaubrun-Diant and Tristan-Pierre Maury (2016) shows the relationship between the purchase of stocks and the purchase of houses in the household asset portfolio [8]. To allow the purchase decisions about houses and stocks to be simultaneous and endogenous, this paper empirically analyzes the interaction between household participation in the stock market and or the decision to buy real estate. Social interaction also significantly improves the possibility and degree of family participation in commercial insurance ( $\mathrm{Li}$ Ding et al., 2019) [9].

In addition to the above factors, financial literacy or financial knowledge is also an important factor affecting a family's financial asset selection. Some scholars at home and abroad have demonstrated the influence of "financial literacy" on the allocation of family financial assets, and they believe that financial literacy is the basis of family financial decision-making. The higher the family financial literacy is, the more likely and deep it is to participate in the risky financial market (Lusardi and Mitchell, 2014) [1]. Yin Zhichao et al. (2014) found that the increase of financial knowledge significantly promoted household financial market participation and risk financial asset allocation [14]. Fonseca et al. (2012) found that financial knowledge is professional knowledge gained from professional experience, and there are gender differences. Men usually have more specific financial knowledge (investment and tax), while women tend to focus on short-term planning and spending in daily life (daily bill payment) [11]. Hu Zhen et al. (2018) found that financial literacy has a significant positive impact on family financial portfolio diversity, and subjective financial literacy has a greater impact on financial portfolio diversity than objective financial literacy [7]. Zhang Ji et al. (2020) believe that financial literacy can significantly reduce the degree of household financial vulnerability and improve the ability to respond to risk shocks [15]. In addition, the improvement of financial literacy can also promote the possibility of households to obtain loans and reduce the interest rate of households' comprehensive loans (Wu Weixing et al., 2019) [13].

Among the existing studies on inclusive finance and household financial asset selection, some scholars' studies show that traditional inclusive finance significantly increases the possibility of household participation in risky financial market and the proportion of risky financial asset allocation (Zhang Xiaomei et al., 2020) [16], and some scholars who combine the development of digital economy and intelligent industry concluded that digital inclusive finance has the same positive correlation with household risk financial market participation (Zhou Yuqing and He Guangwen, 2020) [17]. As to sample selection for households, the vast majority of research has focused on rural households, or in the rural and urban household heterogeneity in inclusive financial aspects, for example, non-farm payrolls householder to research on the effects of family asset allocation (yongbo ge, etc., 2021) [4].

Based on the Chinese family financial investigation (CHFS) in 2017, the latest data, combining both digital Internet factors such as the Internet reason property balance and traditional sense of financial indicators which used to measure the level of inclusive finance, using Probit and Tobit model to study the influence of inclusive finance on household risk assets allocation and analyze its effect mechanism from the differences between levels of Income differences and regions, this paper further proves that the utility of inclusive finance in rural area, central and western China and other relatively less developed regions. It also illustrates the significance of financial literacy by Heterogeneity analysis and mechanism analysis, providing reference to the development plans of inclusive finance.

\section{Methodology}

\subsection{Model Specification}

Probit model and Tobit model are selected to do further empirical analysis, because whether households participate in the financial market is a problem with binary results, and the characteristics of Probit model can well meet the research needs.

$$
\mathrm{P}(\text { risk_asset_a }=1)=\Theta\left(\beta_{0}+\beta_{1} \text { FINDEX }+X \gamma_{i}+\mu_{i}\right)
$$


Where, the dependent variable risk_asset_a represents whether the family participates in the stock market or the risk financial market. If the family participates in the stock market or the risk financial market, the value of the dependent variable risk_asset_a is 1; otherwise, it is 0 . FINDEX is the explanatory variable calculated by factor analysis and details will be explained later. In this paper, it refers to the financial inclusion index. $\mathrm{X}$ is the control variable matrix, which can control the influence caused by other factors and will be explained in details later. $\theta$ is the cumulative distribution function of the standard normal distribution and $\mu$ indicates residual.

In the study of the impact of inclusive finance on the proportion of household allocation of stock assets and risky financial assets, due to the large number of extreme values of 0 in the dependent variable prop_risk, which is the proportion of risk asset in all kinds of financial assets hold by households, the characteristics of the left trunked Tobit model can meet the research needs, i.e. Other variables are the same as the Probit model.

$$
\text { Prop_risk }=\beta_{0}+\beta_{1} \text { FINDEX }+X \gamma_{i}+\mu_{i}
$$

\subsection{Variables Selection}

\subsubsection{Interpreted Variable}

This paper studies the family financial asset selection behavior from two levels: the first level is whether the family participates in the risk financial market; The second level is the proportion of households' allocation of risky financial assets to total financial assets. Therefore, whether households participate in the risky financial market and the proportion of risky financial assets allocated by households to the total financial assets are selected as the explained variables. In this paper, including the risk to the financial assets in the financial assets, cash and stock account cash, government bonds, demand deposits and time deposits, etc., the risk of financial assets including stocks, funds, financial bonds, corporate bonds, financial services, financial derivatives, gold, foreign exchange, etc. Whether households participate in risky financial markets is a variable with the value of 0 and 1. When households hold at least one risky financial asset, the variable has the value of 1 . Otherwise, the value is 0 . The proportion of risky financial assets is expressed as its actual proportion to total financial assets, ranging from 0 to 1 .

\subsubsection{Explanatory Variable}

The main explanatory variable of this paper is the financial inclusion index, which is constructed through factor analysis. Considering the construction methods of existing literatures and the data available in this paper, 12 indicators were used to construct the financial inclusion index, including the average number of bank card hold per household (mcard), average household deposits (msave), average household loans (mloan), average monthly repayment of loans (mcredit), distance from household to the nearest financial intermediary (mdistan), average balance of Internet financial products per household (mfinprod), proportion of households with deposits (saverate), proportion of households with loans (loanrate), proportion of households with credit cards (creditrate), proportion of households with financial products (fprodrate), the proportion of households with commercial insurance (satisrate) and bank service satisfaction (insurrate). All of these factors are calculated according to the dividend of prefecture level and to the difference of rural and urban areas because of the limit of data from CHFS. See Table 1 for specific descriptive statistical results.

Table 1. Descriptive statistics of 12 indicators selected in the factor analysis of financial inclusion index.

\begin{tabular}{|c|c|c|c|c|c|c|}
\hline variable & comments & $\mathbf{N}$ & Mean & Sd. & Min & Max \\
\hline mcard & average number of bank card hold per household & 40011 & 2.5072 & 0.7200 & 0.4091 & 4.9048 \\
\hline msave & average household deposits & 40011 & 47546.35 & 39180.42 & 454.15 & 267941.2 \\
\hline mloan & average household loans & 40011 & 35340.5 & 42121.57 & 0.0000 & 356735.9 \\
\hline mcredit & average monthly repayment of loans & 40011 & 125.9324 & 217.6105 & 0.0000 & 3024.00 \\
\hline mdistan & distance from household to the nearest financial intermediary & 15014 & 5.1687 & 4.5597 & 0.7722 & 40.1409 \\
\hline mfinprod & average balance of Internet financial products per household & 40011 & 2539.042 & 3534.578 & 0.0000 & 28251.22 \\
\hline saverate & proportion of households with deposits & 40011 & 0.6663 & 0.1273 & 0.1667 & 0.9155 \\
\hline loanrate & proportion of households with loans & 40011 & 0.1115 & 0.0695 & 0.0000 & 0.4839 \\
\hline creditrate & proportion of households with credit cards & 40011 & 0.1958 & 0.1252 & 0.0000 & 0.7830 \\
\hline fprodrate & proportion of households with financial products & 40011 & 0.0409 & 0.0465 & 0.0000 & 0.1981 \\
\hline satisrate & the proportion of households with commercial insurance & 40011 & 0.1951 & 0.2880 & 0.0000 & 0.9524 \\
\hline insurrate & bank service satisfaction & 40011 & 0.1470 & 0.0776 & 0.0000 & 0.4906 \\
\hline
\end{tabular}

In order to adopt factor analysis method to extract factors from 12 indicators to summarize the original information, we should first check whether there is a strong correlation between the original indicators. In this paper, KMO test and Bartlett's test are used for correlation test, and the results are shown in Table 2.

Table 2. Result of KMO and Bartlett test of factor analysis.

\begin{tabular}{lll}
\hline KMO and Bartlett test & & \\
\hline Kaiser-meyer-olkin measure of sampling adequacy & & 0.897 \\
Bartlett test & $\chi^{2}$ & 127358.683 \\
& DOF & 66 \\
& P-value & 0.000 \\
\hline
\end{tabular}


The KMO value of the test result is 0.897 , indicating that the correlation between the original variables is strong and can be used for principal component analysis. Bartlett's test results show that the observed value of the statistic is relatively large and lower than the given significance level, indicating that the null hypothesis should be rejected, that is, the correlation coefficient matrix is not an identity matrix, so it is suitable for further factor analysis.

After standardized, principal component method is used to extract the common factors. According to the study of Liu Guoqiang (2018) [10], most information can be effectively covered when the cumulative variance contribution rate of common factors reaches more than $60 \%$. In this paper, three common factors were extracted, and the cumulative variance contribution rate reached $71 \%$.

From the scree plot (seen figure 1), the three factors selected in this paper have included all cases with eigenvalues greater than 1 , and can cover most of the information, making factor analysis appropriate to be used to calculate inclusive financial index.

After rotating the Common factor score coefficient matrix, inclusive financial index can be predicted by SPSS17, the calculation formula is as follow.

$$
F_{i j}=a_{1 j} z_{i 1}+a_{2 j} z_{i 2}+\cdots+a_{12 j} z_{i, 12}
$$

In the formula, $F_{i j}$ is the score of the ith sample on the $j$ th common factor, $\mathrm{a}_{\mathrm{mj}}$ indicates the score of the mth indicator on the $\mathrm{jth}$ common factor, and $\mathrm{Z}_{\mathrm{im}}$ shows the score of the mth indicator of the ith sample after standardized. The variance contribution rate of each common factor is taken as the weight, multiplied by the score of each common factor, and the comprehensive score of inclusive finance index FINDEX is obtained after accumulation. The variance contribution rate is $0.3520,0.2083$ and 0.0925 , respectively. The equation can be explained as:

$$
\operatorname{FINDEX}=\left(\sigma_{1} F_{i 1}+\sigma_{2} F_{i 2}+\sigma_{3} F_{i 3}\right) / \sum_{1}^{3} \sigma_{j}
$$

eigenvalue

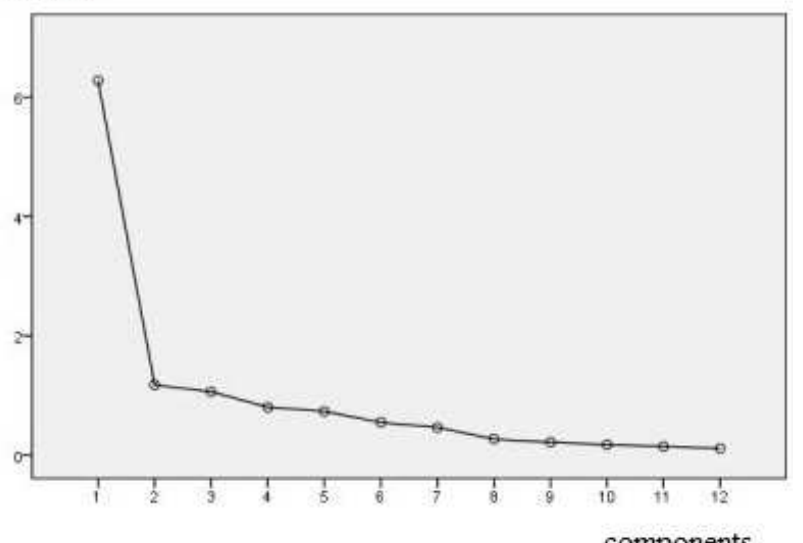

Figure 1. Scree plot of factors analysis.

The index indicates the level of inclusive finance development, i.e. the larger the value of the index, the higher the level of financial inclusion. The descriptive statistical analysis is as follows, seen Table 3 .

Table 3. Descriptive statistical results of the Financial Inclusion index FINDEX.

\begin{tabular}{llllll}
\hline variable & $\mathbf{N}$ & Mean & Sd. & Min & Max \\
\hline FINDEX & 40,011 & 0.269 & 0.136 & 0 & 1.000 \\
\hline
\end{tabular}

\subsubsection{Control Variable}

The control variables are selected on the basis of reference to existing research results, including household head information, family economic status, family demographic structure, self-owned housing, insurance participation, social capital, risk attitude and other categories. Specifically, household head information includes age, gender ( 0 for female, 1 for male), educational attainment (1 to 9 based on education from primary school to $\mathrm{PhD}$ ) and health status (0 for poor health, 1 for otherwise); Whether to participate in commercial insurance (participation in commercial insurance value is 1 , otherwise it is 0). Family financial condition includes net asset and total income; Family population structure includes the total number of family population, the proportion of children (under 16 years old) and the proportion of elderly (over 60 years old); whether household have the ownership of a house ( 0 for on and 1 for yes); Social capital is measured by whether a family member is engaged in the financial industry (if a family member is engaged in the financial industry, the value is 1 ; otherwise, it is 0 ). Risk attitudes are determined by the relevant questions in the China Household Finance Survey (CHFS). In addition, in addition to the family's own factors, this paper also considers that the economic factors of the province may affect the family's choice of financial assets, and selects the per capita income of a province to control the economic factors of a province.

\subsection{Data Source}

The data used in the empirical analysis in this paper is the survey data of China Household Finance Survey and Research Center in 2017. The sample covers 31 Provinces in China except Hong Kong, Macao and Taiwan, and a total of 40011 households' micro data is collected. The descriptive statistical results of all variables are shown in Table 6.

\subsection{Model Estimation and Results}

\subsubsection{The Impact of Financial Inclusion on Participation in Risky Financial Markets}

Columns 1 and 2 in Table 4 show the corresponding results. It can be seen that the coefficient of the financial inclusion index is positive, indicating that the development of financial inclusion can increase the probability of households to participate in the risk financial market. The empirical results support the above analysis. The marginal impact of inclusive finance on whether a family participates in the risky financial market is 0.026 , and inclusive finance has a significant impact on whether a family participates in the risky financial market. 
Table 4. Result of Probit and Tobit Models.

\begin{tabular}{llll}
\hline Variable & risk_asset_a & margins & prop_riak \\
\hline FINDEX & $0.175^{* * *}$ & $0.026^{* * *}$ & $0.228^{* * *}$ \\
& $(2.74)$ & $(2.74)$ & $(7.21)$ \\
Observations & 39,934 & 39,934 & 39,047 \\
Robust z-statistics in parentheses & & \\
$* * * \mathrm{p}<0.01, * * \mathrm{p}<0.05, * \mathrm{p}<0.1$ & & \\
\hline
\end{tabular}

\subsubsection{The Influence of Inclusive Finance on the Proportion of Stock Asset Allocation and Risk Financial Asset Allocation}

Column 3 in Table 4 shows the impact of inclusive finance on the proportion of risky financial assets allocated by households. It can be seen that the coefficients of inclusive finance index are significantly positive. The marginal impact of financial inclusion on the proportion of risky financial assets allocated by households is 0.228 , indicating that households will increase the proportion of risky financial assets by 0.228 when the financial inclusion index increases by one unit.

\section{Heterogeneity Analysis}

\subsection{Rural and Urban}

We study the different impacts of inclusive finance development on rural and urban areas through the classification regression of rural and urban samples. The regression results show that the increase of financial inclusion level has no significant positive impact on the possibility of urban households to participate in the risky financial market and the proportion of risky financial assets.

For rural households, the development of inclusive finance significantly increases their possibility to participate in the risk financial market, with the marginal effect of 0.024 . The proportion of their risk financial assets in the total financial assets will also increase by 0.697 . This reflects that the development of inclusive finance will have a more significant impact on households in rural areas. See Table 5 for specific results. In the heterogeneity analysis of the urban samples, the coefficient of the financial inclusion index is significantly negative, which is in contradiction with the existing cognition. Therefore, urban samples are continuously divided into groups by various criteria and explore the origin of this contradiction from the characteristics of families.

It is finally found that when the samples are grouped according to whether the head of the household is over 40 years old, the results are shown in Table 7 . When the head of the household is less than 40 years old, the coefficient of the financial inclusion index is significantly positive at the $90 \%$ level. When the head of the household is over 40 years old, the coefficient of the financial inclusion index is significantly negative at $99 \%$. $r$ families. See Table 7 for specific results. To some extent, this reflects that the positive effect of financial inclusion on younger family structure is more obvious than that of elders ones.

Table 5. Heterogeneity analysis of rural and urban households samples.

\begin{tabular}{llll}
\hline Rural samples & & & \\
Variable & risk_asset_a & margins & prop_riak \\
FINDEX & $0.605 * * *$ & $0.024 * * *$ & $0.697 * * *$ \\
& $(2.74)$ & $(2.72)$ & $(5.84)$ \\
Observations & 12,711 & 12,711 & 12,271 \\
Urban samples & & & \\
Variable & risk_asset_a & margins & prop_riak \\
FINDEX & $-0.170 * *$ & $-0.033 * *$ & 0.001 \\
& $(-2.17)$ & $(-2.17)$ & $(0.04)$ \\
Observations & 27,223 & 27,223 & 26,776 \\
Robust z-statistics in parentheses & & \\
$* * * \mathrm{p}<0.01, * * \mathrm{p}<0.05, * \mathrm{p}<0.1$ & & \\
\hline
\end{tabular}

Table 6. Descriptive statistics of all Interpreted Variables and Contral Variables.

\begin{tabular}{|c|c|c|c|c|c|c|}
\hline variable & Comments & $\mathbf{N}$ & Mean & Sd. & Min & Max \\
\hline risk_asset_a & risk asset market participation & 40011 & 0.113 & 0.325 & 0 & 1 \\
\hline prop_risk & proportion of risk asset hold by households & 39,118 & 0.0593 & 0.178 & 0 & 1 \\
\hline age & household head age & 40000 & 59.20 & 14.25 & 7 & 121 \\
\hline age 2 & age squared & 40000 & 3,708 & 1,702 & 49 & 14,641 \\
\hline gender & 0 for female, 1 for male & 40010 & 0.793 & 0.405 & 0 & 1 \\
\hline education & 1 to 9 based on education from primary school to $\mathrm{PhD}$ & 39958 & 3.430 & 1.684 & 1 & 9 \\
\hline health & health status of household head ( 0 for poor health, the larger the healthier) & 40002 & 2.613 & 1.016 & 1 & 5 \\
\hline dinsurance & participation in commercial insurance value is 1 , otherwise it is 0 & 40011 & 0.147 & 0.354 & 0 & 1 \\
\hline population & family population & 40011 & 3.174 & 1.552 & 1 & 15 \\
\hline ratio 16 & the proportion of children (under 16 years old) & 40011 & 0.0772 & 0.138 & 0 & 1 \\
\hline ratio 60 & the proportion of elderly (over 60 years old) & 40011 & 0.390 & 0.412 & 0 & 1 \\
\hline house & whether household own a house & 40009 & 0.0615 & 0.240 & 0 & 1 \\
\hline Rpreference & risk attitudes (risk aversion is 0 , otherwise is 1 ) & 40007 & 0.0354 & 0.185 & 0 & 1 \\
\hline dindustry & whether a family member is engaged in the financial industry & 40011 & 0.0283 & 0.166 & 0 & 1 \\
\hline meanincome & average family income per person by provinces & 40011 & 106258 & 37002 & 56,151 & 207,324 \\
\hline $\ln \mathrm{NA}$ & the logarithm of household net asset & 40,011 & 9.710 & 5.687 & 0 & 17.84 \\
\hline $\ln \mathrm{TI}$ & the logarithm of household total income & 40,011 & 10.56 & 1.983 & -1.743 & 15.96 \\
\hline LNFincom & the logarithm of family income per person & 40,011 & 9.537 & 1.868 & -3.352 & 15.43 \\
\hline
\end{tabular}


Table 7. Heterogeneity analysis of age among urban household samples.

\begin{tabular}{|c|c|c|}
\hline $\begin{array}{l}\text { Samples with } \\
\text { urban househ }\end{array}$ & usehold heads & and less than 40) among \\
\hline Variable & risk_asset_a & margins \\
\hline FINDEX & $0.605^{* * *}$ & $0.024 * * *$ \\
\hline & $(2.74)$ & $(2.72)$ \\
\hline Observations & 12,711 & 12,711 \\
\hline $\begin{array}{l}\text { Samples with } \\
\text { households }\end{array}$ & hold heads ag & 40) among urban \\
\hline Variable & risk_asset_a & margins \\
\hline FINDEX & $\begin{array}{l}-0.170^{* *} \\
(-2.17)\end{array}$ & $\begin{array}{l}-0.033 * * \\
(-2.17)\end{array}$ \\
\hline Observations & 27,223 & 27,223 \\
\hline $\begin{array}{l}\text { Robust z-stati } \\
* * * \mathrm{p}<0.01, *\end{array}$ & $\begin{array}{l}n \text { theses } \\
p<0.1\end{array}$ & \\
\hline
\end{tabular}

After the urban sample is grouped according to income, the impact of the development of inclusive finance on high-income families is not significant, while the impact on urban low-income families is significantly negative. See Table 8 for specific results. According to the research of $\mathrm{Hu}$ Zhen and Zang Lihong (2016) [7], it is believed that overconfidence in financial literacy increases risk preference and has a significant positive impact on stock market participation and stock allocation ratio. In terms of shareholding households, overconfidence of financial literacy mainly affects the households with low and high shareholding ratios, but has little impact on the middle level households, with the "U-shaped" characteristics.

Table 8. Heterogeneity analysis of income among urban household samples.

\begin{tabular}{|c|c|c|}
\hline \multicolumn{3}{|c|}{ Samples with higher income among urban households } \\
\hline Variable & risk_asset_a & margins \\
\hline \multirow[t]{2}{*}{ FINDEX } & $0.2 \overline{15}$ & 0.067 \\
\hline & $(0.255)$ & $(0.255)$ \\
\hline Observations & 1,441 & 1,441 \\
\hline \multicolumn{3}{|c|}{ Samples with lower income among urban households } \\
\hline Variable & risk_asset_a & margins \\
\hline \multirow[t]{2}{*}{ FINDEX } & $-0 . \overline{4} 44 * *{ }^{-}$ & $-0.457 * * *$ \\
\hline & $(0.0844)$ & $(0.0844)$ \\
\hline Observations & 25,749 & 25,749 \\
\hline
\end{tabular}

Here, in our opinion, due to the influence of financial literacy in risk appetite has u-shaped relationship, given the town the cost of living is higher and factors such as raising pressure and life pressure of low-income families, inclusive financial development probably makes the risk and uncertainty in the financial market further understanding, and may lead to a significantly lower risk appetite, so the positive effects of other factors are offset, resulting in a lower willingness to participate in the risk financial market.

As for the above problem that the development of inclusive finance changed the understanding of risk uncertainty of families and led to the change of their participation in the risk financial market, we grouped regression according to the level of families' financial literacy. The results show that in households with high financial literacy, the negative effect of the development of inclusive finance is not significant, but in households with low financial literacy, the impact is significantly negative at the level of $90 \%$, which also shows from the side that the effect of inclusive finance is limited by the financial literacy of the audience, so the popularization of financial knowledge, improving residents' financial literacy plays a crucial role in the development of inclusive finance. See Table 9 for specific results.

Table 9. Heterogeneity analysis of financial literacy among urban household samples.

\begin{tabular}{|c|c|c|}
\hline Samples with 1 & hold head final & among urban households \\
\hline Variable & risk_asset_a & margins \\
\hline FINDEX & -0.146 & -.0335 \\
\hline & $(0.0914)$ & $(0.0914)$ \\
\hline Observations & 17,106 & 17106 \\
\hline Samples with 1 & old head finan & mong urban households \\
\hline Variable & risk_asset_a & margins \\
\hline FINDEX & $-0.268 *$ & $-.0355^{*}$ \\
\hline & $(0.160)$ & $(0.160)$ \\
\hline Observations & 10084 & 10084 \\
\hline Robust z-stati & entheses & \\
\hline$* * * \mathrm{p}<0.01, *$ & $\mathrm{p}<0.1$ & \\
\hline
\end{tabular}

\subsection{Higher and Lower Income Level}

This paper uses the original data of total household income and family size to calculate the per capita income of a family, and compares it with the per capita income of the province in which the family is located. The families whose per capita income is greater than the provincial per capita income are classified as high income families, and the families whose per capita income is less than the provincial per capita income are classified as low income families. By the regression of the two groups of samples found inclusive financial level change for high-income families risks involved in asset markets and the risk assets ratio had no significant influence, for the low-income families, inclusive financial level of ascension will significantly improve the family in the possibility of risk assets and the proportion of risk of financial assets, the marginal effect of 0.021 and 0.242 respectively. However, in the survey data of CHFS2017, there were only more than 1600 samples of high-income families. The insignificant regression results of high-income families may be due to the insufficient sample size, but it also shows that the development of inclusive finance plays a more important role in the participation of low-income families in the financial market to some extent. See Table 10 for specific results.

Table 10. Heterogeneity analysis of higher and lower income samples.

\begin{tabular}{|c|c|c|c|}
\hline \multicolumn{4}{|c|}{ Higher income samples } \\
\hline Variable & risk_asset_a & margins & prop_riak \\
\hline \multirow[t]{2}{*}{ FINDEX } & $0.3 \overline{67}$ & 0.108 & 0.061 \\
\hline & $(1.50)$ & $(1.50)$ & $(0.76)$ \\
\hline Observations & 1,614 & 1,614 & 1,606 \\
\hline \multicolumn{4}{|c|}{ Lower income samples } \\
\hline Variable & risk_asset_a & margins & prop_riak \\
\hline \multirow[t]{2}{*}{ FINDEX } & $0.1 \overline{44} * *$ & $0.021 * *$ & $0.242 * * *$ \\
\hline & $(2.17)$ & $(2.17)$ & $(7.08)$ \\
\hline Observations & 38,320 & 38,320 & 37,441 \\
\hline $\begin{array}{l}\text { Robust z-statis } \\
* * * \mathrm{p}<0.01, *\end{array}$ & $\begin{array}{l}\text { in parenthese } \\
0.05, * p<0.1\end{array}$ & & \\
\hline
\end{tabular}




\subsection{Eastern, Central and Western Regions}

Considering the big differences in economic development between eastern and western regions of China, this paper divided the family samples into eastern, central and western regions according to the location of household registration. The group regression results are displayed in table 11 .

Table 11. Heterogeneity analysis of samples from eastern, central and western regions.

\begin{tabular}{|c|c|c|c|}
\hline \multicolumn{4}{|c|}{ Samples from Eastern regions } \\
\hline Variable & risk_asset_a & margins & prop_riak \\
\hline \multirow[t]{2}{*}{ FINDEX } & 0.013 & 0.003 & $0.153 * * *$ \\
\hline & $(0.18)$ & $(0.18)$ & $(4.47)$ \\
\hline Observations & 20,866 & 20,866 & 20,552 \\
\hline \multicolumn{4}{|c|}{ Samples from central regions } \\
\hline Variable & risk_asset_a & margins & prop riak \\
\hline \multirow[t]{2}{*}{ FINDEX } & $0.9 \overline{72} * * *$ & $0.101 * * *$ & $0.834 * * *$ \\
\hline & $(4.64)$ & $(4.60)$ & $(6.01)$ \\
\hline Observations & 10,887 & 10,887 & 10,592 \\
\hline \multicolumn{4}{|c|}{ Samples from Western regions } \\
\hline Variable & risk_asset_a & margins & prop_riak \\
\hline \multirow[t]{2}{*}{ FINDEX } & $0.637 * * *$ & $0.069 * * *$ & $0.357 * * *$ \\
\hline & $(3.33)$ & $(3.32)$ & $(3.67)$ \\
\hline Observations & 8,181 & 8,181 & 7,903 \\
\hline $\begin{array}{l}\text { Robust z-statis } \\
* * * \mathrm{p}<0.01, *\end{array}$ & $\begin{array}{l}\text { in parenthese } \\
0.05, * \mathrm{p}<0.1\end{array}$ & & \\
\hline
\end{tabular}

It shows that the development of inclusive finance has no significant impact on the financial market participation of households in eastern China, but has a positive impact on the proportion of risky financial assets, with a marginal effect of 0.153 . However, the development of inclusive finance in both central and western regions will increase the possibility of household participation in risky financial market and the proportion of risky financial assets. The marginal effect in central region is 0.101 and 0.834 , which are larger than 0.069 and 0.357 in western region.

We conclusion that this may be because the development of western China is more backward than that of eastern China, and the average household income is relatively low. Therefore, the focus of household demand may be more inclined to stay in the real economy such as production and living, and pay less attention to financial activities. Therefore, vigorously developing inclusive finance in the central region will have a broader and deeper impact on household risk financial market participation and asset allocation ratio..

\section{Mechanism Analysis}

In order to analyze the influence mechanism of inclusive finance on family financial asset selection, this paper adopts the causal stepwise regression test, selects the mediating variable of financial literacy to analyze the mediating effect, and constructs a model:

$$
\text { Finliteracy }=\beta_{0}+\beta_{1} \text { FINDEX }+X \gamma_{i}
$$

The variable of financial literacy (Finliteracy) is derived from the number of finance-related questions respondents answered correctly. The more questions answered correctly by respondents, the higher the value of Finliteracy. Its descriptive statistics are shown in Table 12.

Table 12. Descriptive statistics on financial literacy.

\begin{tabular}{llllll}
\hline variable & N & Mean & Sd. & Min & Max \\
\hline Finliteracy & 40,011 & 0.750 & 0.802 & 0 & 7 \\
\hline
\end{tabular}

The significant impact of financial inclusion levels on household participation in risky financial markets and the proportion of risky asset investments has been identified. Here, the mediating variable of financial literacy is taken as the explained variable, and the financial inclusion index is taken as the explanatory variable.

Exogenous control variables and possible endogenous control variables are added in turn, and regression analysis is conducted with the ordinary least square method. The results in table 13 show that there is a significant positive correlation between the financial inclusion index and financial literacy..

Table 13. Result of stepwise regression to recognize Mediating Effect.

\begin{tabular}{llll}
\hline Variable & risk_asset_a & margins & prop_riak \\
\hline FINDEX & $0.057 * *$ & $0.172 * * *$ & $0.228 * * *$ \\
& $(2.04)$ & $(2.68)$ & $(7.27)$ \\
Finliteracy & & $0.155^{* * *}$ & $0.093 * * *$ \\
Observations & 39,934 & 39,934 & 39,047 \\
R-squared & 0.133 & & \\
t-statistics in parentheses & & \\
$* * * \mathrm{p}<0.01, * * \mathrm{p}<0.05, * \mathrm{p}<0.1$ & & \\
\hline
\end{tabular}

Further tests show that financial literacy has a significant positive impact on the participation of households in risky financial markets and the proportion of risky financial assets at the level of $99 \%$. The tests of the two links show that the mediation effect is partly significant, and the inclusion of finance affects the household participation in risky financial market and the proportion of risky financial assets by improving financial literacy. See Table 13 for specific results.

\section{Endogeneity and Robustness Test}

\subsection{Endogeneity}

Endogeneity problems mainly come from three aspects: reverse causality, missing variables, and measurement errors. The financial inclusion index in this paper is constructed based on a sample of 40011 households from the China Household Finance Survey (CHFS) in 2017, using 12 relevant indicators. Therefore, it can be considered that the influence of a single sample on the overall macro financial inclusion index is ignored, so the path of reverse causality leading to endogeneity is excluded.

Due to the limitation of the index structure and the number of control variables, the omission of variables and measurement errors are likely to cause potential endogeneity problems, so the instrumental variable method is used. Inclusive finance goes up in the breadth and depth of understanding, and the present social inclusive finance is easy to be saturated, so pay more attention to the longitudinal hierarchy (inclusive financial) of digging, and the number of 
smart phones and digital inclusive financial, namely the more the number of smart phones within a certain scope, the stronger the residents' financial application depth, inclusive financial level with positive change. Some scholars have proposed the idea that the number of smartphones can be used as an instrumental variable of digital inclusive finance, so the instrumental variable selected in this paper is the number of smartphones in each family.

Through the Weak identification test of the Probit model and Tobit model, the $F$ value is 101.9 and 94.5 respectively (up in Table 14), much larger than 10. Therefore, it can be considered that there is no weak instrumental variable, that is, there is a strong correlation between the instrumental variable and the endogenous explanatory variable. The number of smart phones was used as the instrumental variable to carry out the Hausman Test, and the results showed that the P-value values of the two models were 0 (down of Table 14), so the hypothesis of "all explanatory variables are exogenous" could be rejected at the significance level of $99 \%$, and the financial inclusion index FINDEX was considered as an endogenous variable. In addition, empirical results of Wald test rejected the hypothesis that endogenous variables (financial inclusion index) were exogenous. In order to ensure the exogeneity of the use of instrumental variables, 14 control variables were added. In conclusion, using the number of smartphones as an instrumental variable can alleviate the endogeneity problem of the model to a certain extent.

Table 14. Result of Weak Identification and Hausman Test.

\begin{tabular}{lll}
\hline Weak Identification Test & & \\
Variable & risk_asset_a & prop_risk \\
Observations & 39,768 & 38,888 \\
R-squared & -2.760 & 101.9 \\
Weak identification test & -2.194 & 94.50 \\
Hausman Test & & \\
Variable & risk_asset_a & prop_risk \\
Observations & 39,768 & 38,888 \\
Hausman & 379.8 & 266.4 \\
p-value & 0 & 0 \\
\hline
\end{tabular}

\subsection{Robustness}

In order to test the robustness of the empirical results, the financial inclusion index of Peking University (PKUIf) is used to replace the financial inclusion index constructed in the previous paper. The digital financial inclusion index was compiled by the research group of The Digital Finance Research Center of Peking University [3]. The provincial digital financial inclusion index was selected in this paper. The compilation method of the index is different from the construction method of the financial inclusion index in this paper, and the factor of digital finance is taken into account. Therefore, the digital financial inclusion index can test whether the results of this paper are robust to a certain extent. The regression results are shown in Table 15. It can be seen that digital financial inclusion has a positive impact on whether households participate in the risk financial market, and the marginal impact is 0.008 respectively, both significant at the $99 \%$ level. Digital financial inclusion also has a positive impact on the proportion of household risky financial assets, and the marginal impact is 0.006 , both of which are significant at the $99 \%$ level. The results obtained are basically consistent with the previous results, indicating that the conclusions obtained in this paper are robust to a certain extent.

Table 15. Result of Robustness Test by substituting PKUIF for FINDEX.

\begin{tabular}{llll}
\hline Variable & risk_asset_a & margins & prop_riak \\
\hline PKUIf & $0.008^{* * *}$ & $0.008^{* * *}$ & $0.006^{* * *}$ \\
& $(7.34)$ & $(7.34)$ & $(12.63)$ \\
Observations & 39,934 & 39,934 & 39,047 \\
Robust z-statistics in parentheses & & \\
$* * * \mathrm{p}<0.01, * * \mathrm{p}<0.05, * \mathrm{p}<0.1$ & & \\
\hline
\end{tabular}

\section{Conclusion}

This paper studies the impact of inclusive finance on household financial asset selection with a different inclusive finance index, proves the influence of inclusive finance on household financial asset allocation, recognizes factors which should be taken seriously while developing inclusive finance and finally gives out suggestions. Through empirical analysis with latest data, it is further confirmed that financial inclusion influences household participation in risky financial market and proportion of risky financial assets through improving financial literacy. Increasing the level of financial inclusion will increase the probability of households participating in the risky financial market, and at the same time, financial inclusion can increase the proportion of households to allocate risky financial assets.

The results of analysis of heterogeneity show that the increase of inclusive financial level does not have an obvious positive relation to the possibility of financial risk market participation for urban households. But if urban households can get higher income, higher level of financial literacy or younger age structure, inclusive finance can be more effective in the impact on risk financial market participation. So as stated earlier, at the same time of developing the inclusive finance, more attention should be paid to the protection of residents' basic needs and level of economic development. For rural households, the development of inclusive finance will significantly increase the possibility of their participation in risky financial markets and increase the proportion of investment in risky financial assets. At the same time, the change of financial inclusion level has no significant impact on the market participation of risky assets and the proportion of risky assets of high-income households, while for low-income households, the improvement of financial inclusion level will significantly increase the possibility of household participation in risky assets and the proportion of risky financial assets.

The difference between rural and urban areas is a long-lasting issue in China and even around the globe. In our research, we only test the several important factors which may lead to the irregular result from urban households. Deeper studies should be made to comprehensively reveal the 
pattern of the influence of financial inclusion by using more complex none-linear models and by forthcoming data.

In addition, the development of inclusive finance has no significant impact on the financial market participation of households in eastern China, but has a positive impact on the proportion of risky financial assets. The development of inclusive finance in central and western regions will increase the possibility of household participation in risky financial market and the proportion of risky financial assets.

The implementation of inclusive finance policy can increase the probability of households to participate in the risky financial market, increase the proportion of households to allocate risky financial assets and promote the diversification of family financial assets. The implementation of financial inclusion policies has improved the financial literacy of families, thus increasing the probability that families participate in the risky financial market and enabling families to allocate financial assets more reasonably. Improved financial literacy also allows financial inclusion to play a more visible role.

The effect of financial inclusion policy is more obvious in rural families, low-income families and the Midwest. With China's economic and social development, the income of rural households has increased significantly, and the surplus wealth needs to be invested. However, from the current situation, the proportion of Chinese rural households to participate in the risky financial market is still relatively low, and the types of financial assets allocated are relatively single. More attention should be paid to the development of inclusive finance in rural areas, central and western regions and low-income groups, so as to increase the diversity of financial asset portfolio of rural households. The financial inclusion policy can promote households to allocate financial assets more reasonably, thus increasing the income of households' financial assets. In terms of the overall financial market, the implementation of financial inclusion policy can increase the number of participants in the financial market, make the secondary trading market more active, and promote the improvement of financial system.

\section{References}

[1] Annamaria Lusardi; Olivia S. Mitchell; Vilsa Curto, Financial literacy and financial sophistication in the older population [J], Journal of Pension Economics and Finance Volume 13, Issue 4. 2014. PP 347-366.

[2] Carol C. Bertaut, Michael Haliassos, Precautionary portfolio behavior from a life-cycle perspective [J], Journal of Economic Dynamics and Control Volume 21, Issue 8. 1997. PP 1511-1542.

[3] Digital Finance Research Center of Peking University [R], Digital Financial Inclusion Index of Peking University, (The third edition, 2011-2020), 2020.
[4] Ge Yongbo, Chen Hongyu, Zhao Gouqing, Non-Agricultural Employment and Rural Household Financial Asset Allocation from the Perspective of Financial Exclusion [J], Modern Economic Science, 2021, 43 (03), PP 16-31.

[5] He Wei, Wang Xiaohua, Rearch Progress On Household Financial Asset Selection and Influencing Factors [J], Chinese Review of Financial Studies, 2021, 13 (01), PP 95-120+124.

[6] $\mathrm{Hu}$ Zhen, Financial Literacy and Household Wealth Accumulation: Based on Micro-data from Urban Household in China [J], Journal of Zhongnan University of Economics and Law, 2018, (04), PP 110-117.

[7] Hu Zhen, Zang Rihong, Risk, Financial Education and Household Financial Market Participation [J], Statistical Research, 2016, 33 (12), PP 67-73.

[8] Kevin. E. Beaubrun-Diant; Tristan-Pierre Maury, Home tenure, stock market participation, and composition of the household portfolio [J], Journal of Housing EconomicsVolume 32, 2016. PP 1-17.

[9] Li Ding, Ding Junsong, Ma Shuang, The Effect of Social Interaction on Household Commercial Insurance Purchases: Evidence from the China Household Finance Survey [J], Journal of Financial Research, 2019, (07), PP 96-114.

[10] Liu Guoqiang, A Study of Financial Literacy in China: Based on the 2017 Financial Literacy Survey [J], Journal of Financial Research, 2018 (03), PP 1-20.

[11] Raquel Fonseca, Kathleen J. Mullen, Gema Zamarro, Julie Zissimopoulos, What Explains the Gender Gap in Financial Literacy? The Role of Household Decision Making [J], Journal of Consumer Affairs Volume 46, Issue 1. 2012. PP 90-106.

[12] State Council of the People's Republic of China, Implementation of the Financial Inclusion Development Plan (2016-2020), 2016.

[13] Wu Weixing, Zhang Xuyang, Wu Kun, The Impact of Financial Literacy on Family Debt Behavior: An Analysis Based on Heterogeneity of Family Loan [J], Research on Financial and Economic Issues, 2019, (05), PP 57-65.

[14] Yin Zhichao, Song Peng, Huang Qian, The Credit Constrains and Assets Choice of a Household — the Empirical Research on Data from China Household Finance Survey [J], Review of Investment Studies, 2015, 34 (01), PP 4-24.

[15] Zhang Ji, Yu Meng-Di, Cao Yang, Financial Literacy and Household Financial Fragility [J], Jilin University Journal Social Sciences Edition, 2020, 60 (04), PP 140-150+238.

[16] Zhang Xiaomei, Dong Wenkui, Han Kefei, an analysis of influence of inclusive finance on household financial assets selection and its mechanism [J], Contemporary Finance \& Economics, 2020 (01), PP 65-76.

[17] Zhou Yuqing, He Guangwen, the effect of digital inclusive finance development on farmers' household financial assets allocation [J], Modern Economic Science, 2020, 42 (03), PP 92-105. 